somewhat fierce light, on the work of hospitals: and the laws, which have governed the life of many inmates in the past, are in process of being changed. It is therefore inevitable that hospital psychiatrists too will be expected to collaborate more with people in the community and there is no reason why they should not do so as well as their colleagues, and they themselves, did in the War. The fashion is growing for lay people to have more of a say in the control of hospitals, even mental hospitals, and clearly they have contributed much. They will do more, if they have the guidance and good will of the experienced doctors on the spot.

New legislation is likely to encourage patients to seek treatment earlier : and the psychiatrists' work will therefore become focussed increasingly on this-the more so since he has been armed with more effective weapons, both drugs and techniques. It is indeed possible that he may be overwhelmed by too many demands for his help. In any case he will certainly gain from collaborating with all he can-social workers of all kinds, personnel officers, probation officers, clergy and of course; general practitioners. But in doing so he will again meet the resistances which he met in the War and he must be prepared to be as patient and persistent as he was then.

\title{
GHANGES IN THE JOURNAL
}

This Journal is changing its form to try to meet the ever increasing public interest in mental disorder or mental health. We shall this year produce four issues instead of three, and each issue will deal principally with one major topic on which we shall invite experts to contribute special articles.

In this current issue we have focused attention on the "Mental Health Bill". The summer issue will concentrate on "Work", the subject of the N.A.M.H.'s Annual Conference on March 19th and 20 th.

\section{"Forum"}

This is a new contemporary in the field of education to which we extend a welcome.

Its aim is to provide a platform for the discussion of "New Trends in Education". Its two Editors are both on the staff of the Education Department, University of Leicester.

Copies can be obtained from the Manager, 71 Clarendon Road, Leicester, price $3 \mathrm{~s}$., or for three issues, $8 \mathrm{~s}$. 6d. 